\title{
The Subjective Aspects of Pain and its Objectivity in Research
}

\author{
Laurence Croix ${ }^{*}$
}

Center for Research in Psychoanalysis, Medicine and Society of the University of Paris Diderot University at Sorbonne Paris Cité (EA 3522), France

\begin{abstract}
Based on a research and clinical work conducted in a pain treatment centre in France, the author shows that the conceptual dichotomies of psyche-soma that dominate the current discussion of the phenomenon of pain cannot ultimately account for its clinical realities. Although pain manifests in the body, it cannot be reduced to organic causes. The psychoanalytic approach to the body on the other hand allows us to make sense of the reality of pain, of the objectivity and certainty that mark its experience for the suffering subject and, in parallel, of the cases where no organic substrate has been identified. The body is not only organic. It is then up to the clinician, whether a physicalist or a psychoanalyst, to know how to work with this sign - one that does not call for interpretation -- regardless of its presumed aetiology.
\end{abstract}

Keywords: Body, objectivity/subjectivity, pain, phantom limb, psychalgy, reality.

\section{INTRODUCTION}

"Pain in its radical, elemental form - the form which is the essence of torture - was the stumbling block and the death of all philosophies".

[Raymond Queneau] [1]

It is difficult for any conceptual approach, whether it be moral, philosophical, psychological, physiological, biological, etc., to account for the highly complex and diverse clinical realities of the phenomenon of pain. Certain conceptual frameworks that strive after scientific objectivity tackle the problem by trying to describe and categorize different kinds of pain, as one might do with symptoms or diseases. They do so according to a pre-established aetiology, which may be either physical (the so-called "real" or "typical" pain), psychic ("psychogenetic pain" or "psychalgia") or "moral pain," also described as "atypical" or "imaginary." However, the question is whether these kinds of descriptions lead to a clearer and more objective conceptualization of pain, or offer greater therapeutic efficacy.

This terminological game seems intent on separating subjectivity from the experience of pain. Using a positivist approach, it seeks to identify an organic source, in order to lend credibility to the painful experience, treat it or, in the opposite case, justify a therapeutic failure (by designating the pain in question as purely psychical or imaginary).

However, I would argue that the subjective aspects of pain and the complaint that is usually associated with it cannot be separated from pain itself since any feeling of pain is by definition a phenomenon, affect or experience that belongs to a subject, rather than to a wound, trauma or disease.

*Address correspondence to this author at the Center for Research in Psychoanalysis, Medicine and Society of the University of Paris Diderot University at Sorbonne Paris Cité (EA 3522), France;

Tel: 33-687703088; E-mail: lcroix@noos.fr
Using clinical examples from my previous work [2], I would like to [1] question the phenomenon of pain empirically, looking at the difficulties and impasses of both neurophysiological and psychological theories of pain, and [2] show that Freud's theorisation of the body and its affects can help both clinical practitioners and researchers make sense of the questions of subjectivity in relation to pain.

In conclusion, I argue that rather than thinking of pain as a signal, any painful phenomenon should be understood as a sign -- an objective sign that does not deceive -- regardless of the specifics of its triggering, manifestation or its location in the body.

\section{CLINICAL OBSERVATIONS}

In centres that specialise in the treatment or "management" of pain, the term "psychalgia" is used to describe pains that are poorly defined, topographically atypical and subject to psychological and emotional factors. Psychalgia would then be a pain of unknown origin, which is attributed to a purely psychological process and in some way seen as imaginary.

On the other hand, certain pains are considered as "real" because they are allegedly linked to a bodily trauma, a disease or a physiological dysfunction, in some cases despite a complete lack of evidence to prove this.

However, unless we separate pain from its physiological basis or its presumed organic origin, how do we understand phenomena such as the emergence of pain in a "phantom limb"? And vice versa, how do we grasp other types of conditions, such as insensitivity to pain (analgesia), whether it is congenital, occurs as a symptom in hysteria, or presents on a much larger scale in cases of the Cotard syndrome or autism. These clinical occurrences demonstrate that although pain cannot be disconnected from the body, neither can it be understood as purely organic.

Let us pause here for a moment and consider the cases of the so-called phantom pain -- i.e. pain in the portion of the 
limb that has been removed -- which is systematically experienced by amputees and should be distinguished from residual limb pain, which might instead have to do with nociception. In my previous work [3] I have shown that the experience of a phantom limb is no more a hallucination than any other representation of an actual limb that still exists in physical reality. It simply confirms that the subject's specular image is normal. What we might instead consider as pathological is the absence of the phantom limb phenomenon, for example in cases of psychosis.

The pain that is almost always associated with the phantom phenomenon is not a signal of danger or disease that have been caused by the removal of the limb (as the theory of pain as a warning signal would suggest), but marks the impossible relationship between "psychical reality" (Freud) and the real of the loss. These amputees are neither hallucinating nor deluded. They do not complain about the symptoms, irritations or other sensations the phantom limb causes them. Instead they simply live with them - just like any other subject lives with his own feelings and sensations. At the same time, it seems that the pain in a certain way forces the amputee to become aware of the real; it suggests the impossibility to imagine the absence not in the so-called objective reality but in the inner psychical reality.

Like any other type of pain, these phantom pains therefore vary from case to case in terms of their manifestation (they can be episodic, throbbing, constant, sharp, chronic, etc.), intensity and form (burning sensation, tingling, "stabbing pain," etc.). This obviously makes them neither more nor less imaginary or bearable for the suffering subject than any other type of pain; at the same time, they are precisely localised in the body and clearly unconnected to any organic substrate.

Let us begin our discussion with these phantom pains, which are no doubt the most exemplary. However, we could make the same argument about other types of severe pain that lacks a known or identifiable physiological source yet are very difficult to bear: for example the so-called trigeminal neuralgias (TGNs), tension headaches, migraines or certain types of back pain.

We could also include pains that emerge after a trauma or sometimes following a relatively trivial injury and continue to cause deep suffering to the subject, long after his physical wounds have healed.

The question therefore arises of how or why we diagnose pains that supposedly stem from an organic dysfunction as different from those that originate in the subject's psychical reality. Is this really necessary, and if so, for whom or for what? It has been shown that therapies (both chemical treatments, such as morphine therapy, and others, for example massage therapy) are equally effective regardless of whether the pain treated is considered organic or not. Likewise, we know that even in cases of pain allegedly of physical origin, placebos are just as effective as in the cases of psychalgia.

\section{OBJECTIFYING PAIN: A FUNDAMENTAL IM- PASSE?}

\section{1) A Short History}

At the beginning of our civilization, when Galen became the first to look to pharmacopeia and surgery for ways to fight pain, he situated its centre in the brain as the "seat of sensations."

The beginnings of the modern anatomical approach to pain date back to the Renaissance period, influenced by the Platonic Academy and the works of Leonardo de Vinci. At this time, pain became understood as a sensation passed along the nerve fibres. In the sixteenth century, the French surgeon Ambroise Paré used surgery to treat certain types of pain (including neuralgia and phantom limb pain) in severely wounded soldiers.

We should also mention Descartes's theory of pain as an over-intensification of the sensation of touch, which he saw as connected with the movement of the spirit along the nerves. More specifically, he too was interested in the phenomenon of the phantom limb and stressed the electrical nature of the transmission of nerve impulses.

Although recently we have seen a number of very interesting theories inspired by the Cartesian approach, surgery has provided today's science with an irrefutable proof of there being no specific neural pathway for pain, as Descartes or even some of our contemporaries would believe. If the opposite were true, a surgeon would be able to interrupt its transmission at will and no such phenomenon as the phantom limb would be possible.

In the nineteenth century, pain management made rapid progress thanks to the discovery of hypnosis by Puységur (around 1784), of nitrous oxide by Hichman (1824), of ether by Morton (1846), together with the discoveries of chloroform, aspirin (1895) and veronal (1903).

At the beginning of the twentieth century, psychoanalysis and experimental medicine put an end to some of the illusions of the doctrine of vitalism, namely the idea of the "spontaneity of living beings." These notions were disputed by, among others, the French physiologist Claude Bernard, who wrote: "We must believe in science, i.e. in determinism; we must believe in a complete and necessary relation between things, among the phenomena proper to living beings as well as in all others." [4]

By denouncing the notions of free will, chance and destiny as illusions, Freud, who initially trained as a neurologist, aimed to include his new science of psychoanalysis under this same banner, arguing that "determinism in the psychical sphere is [...] carried out without any gaps" [5] and that psychoanalysis is distinguished by its "strict and universal application of determinism to mental life" [6].

\section{2) The Determinism(s) in Question}

We should remember that for both Bernard and Freud, there still exists an undetermined remainder to mental phenomena. For Bernard, this is due to their complexity, which "experimental analysis" aims to break down into increasingly simpler units, eventually reducing them to basic elements. Bernard criticizes the German "physicalists," who see vital phenomena as merely physiochemical reactions -- in his view biology must instead retain its own specific processes and laws. The same is true for Freud, who clarifies and defends the hypothesis of an intra-psychical determinism functioning according to its own laws. 
However, the further medicine progresses, the more obviously it forgets that, as Georges Canguilhem remarked and this is true not only with respect to pain -- "it is particularly the sick man's point of view which forms the basis of truth."[7].

On the contrary, Freud argues from the earliest stages of his new discipline (in the 1895 Studies on Hysteria [8], where he takes a position different to Bernard) that we should consider the patient's suffering as paramount: by listening to him carefully and keeping in mind that "the complete consent and complete attention of the patients are needed, but above all their confidence." We should add that we must also avoid any moral judgement, especially regarding the credibility of the patient's discourse and experience.

The fact is that both before and after the diagnosis has been established it is the subject who suffers from pain, in his arm or leg, as need be. When we ask the question: "Where does it hurt?" we assume that the feeling of pain belongs to the subject and not the arm or the leg itself. This semantic detail ${ }^{1}$ is more obvious in English than in French, for example using the noun ache (as in to have a headache). The verb to have attributes the pain to the subject rather than to the painful limb itself, while ache emphasizes action, the fact of causing pain by someone or something that remains undetermined. Is it the task of the clinician or the researcher to use theory to identify this unknown remainder?

In other words, the distinction between physiological and mental pain is purely speculative. Pain is unique also insofar as it is always conscious and located in or on the body [9].

\section{THE BODY OF PAIN}

\section{1) Clinical Example}

According to the physician who had referred her to me, Mrs S was suffering from "psychalgia." At about fifty years old, she had been diagnosed with cancer in the right breast and at the same time a sharp pain appeared in her arm, extending from the wrist to the right elbow. Her doctors connected the pain to her initial illness, although they considered it "uncharacteristic."

Mrs S. underwent a mastectomy of her right breast, which had absolutely no effect on the pain - the latter remained equally strong and located in the same place throughout the following twenty years.

At seventy years old and shortly after we had started our sessions, Mrs S was able to associate the painful sensation with the most traumatic event of her life. When she was twenty years old, she found herself in the street during an air bombing, lying on the ground with her mother and sister. "When I got back on my feet, both my mother and sister were dead. I escaped without a scratch."

The case shows us that, first, the chronic pain experienced by the patient was completely unrelated to her illness, and second, that it was a sign of a psychically traumatic event a priori as real as her cancer. We also see that the chosen body part, in this case her arm, symbolically stands for "the mother's arms." How and why did the pain appear con-

\footnotetext{
${ }^{1}$ See my discussion of "semantic considerations" in French, German and English in Croix [3], p. 59.
}

secutively with her breast cancer has to do with other signifiers and events the discussion of which goes beyond the scope of this paper.

What we should remember is that in this case the patient's pain was "physical," in the sense that it was located in the body, but it was not organic (she had not actually suffered any physical injury to her arm), which made it no less real than, for instance, pain caused by a broken arm, by cancer or some other organic damage. The war did in fact happen and she really did live through the event of a bombing, lying on the ground with her mother and sister.

We must therefore return to the question of what is a body, in order to try and understand the so-called "physical" substrate of pain differently.

\section{2) The Body as Reality}

To say that the body is a reality does not mean that it is only organic or that it can be reduced to its material aspects if this was so, it would be nothing but a pound of flesh or a piece of meat.

Instead it is to say that as a reality, the body has a subordinate status: it is something constructed and secondary. Rather than being a primary fact, it is a kind of "superstructure," meaning that it is always already marked by the relations defining our psychic structure. We are therefore not born with a body, but construct it -- this argument was put forward already in the 1930s by the work of Paul Schilder and today it is in principle agreed on even by neurologists [10].

By striving towards the real, science shows us that there is more beyond our reality. The real therefore acts as a counterweight to reality. Both philosophy and the natural sciences conceive of it as something inaccessible or impossible; in psychoanalysis, we would call this an impasse of meaning or of formalization.

Psychoanalysis too lets us grasp something of the body that is real, in other words, something that lies beyond its initial idea as simply a reality. Though the contrast between reality and the real deserves a much more detailed discussion, for the purposes of my argument it suffices to say that it allows us to distinguish between, on the one hand, the living organism and, on the other hand, what we call the body. The living organism is not the body. The body is a reality in the sense of its being a psychic construction.

It is of course true that we need the living organism in order to have a body -- but we also need an image to give it the feeling of unity, which is in itself a complicated phenomenon. The French psychoanalyst Jacques Lacan argued that it was the effect of a visual gestalt, in a moment when the subject grasps the unity of his form in the mirror. In other words, he contrasts the unity and unicity of the image with the organism left to his own devices, which at this point could be best described as premature. He speaks about a certain malaise or dehiscence at the very heart of the organism, insofar as it lacks the coordination provided by the image. The latter allows it to grasp itself as a totality, freeing the organism from its original fragmented state.

The mirror stage therefore plays an essential function in the birth of the $I$, which is constituted based on this recogni- 
tion of one's body in the mirror. "I have a body," which can cause me pain or give me pleasure; the perceptionconsciousness system, which is at the origin of Freud's work, is always and irreversibly subjective.

In the experience of pain, the body undergoes a kind of anamorphosis, where seemingly only the source of pain remains yet is represented disproportionately. Freud uses the example of a small cavity in a molar, which, once it has become painful, turns into an enormous gaping hole.

The subject no longer exists, or only exists as a victim of the pain. This disintegration of the body image and of the feeling of existence associated with it demonstrates the permanent fragility of the subjectivity connected to the body's psychic construction.

At this level, Freud considers that the construction of the ego does not depend on the reality principle or the preconscious, but on the experience of one's own body. He writes:

"A person's own body, and above all its surface, is a place from which both external and internal perceptions may spring. It is seen like any other object, but to the touch it yields two kinds of sensations, one of which may be equivalent to an internal perception. Psychophysiology has fully discussed the manner in which a person's own body attains its special position among other objects in the world of perception. Pain, too, seems to play a part in the process, and the way in which we gain new knowledge of our organs during painful illnesses is perhaps a model of the way by which in general we arrive at the idea of our body" [11].

\section{PAIN IS AN OBJECTIVE SIGN}

In closing, regarding the apparent dichotomy between the psyche and soma, which seems to lead the current discussion of pain into a clinical and theoretical impasse, we would add that, in general, conflating the body with the organic means reducing the human being to matter alone. This fetishization of the body not only leads to a narrow view of psychoanalysis as incompatible with the so-called "hard" sciences, but most importantly it prevents us from truly hearing the patient's discourse and grasping the "real" pain of his suffering.

Since Freud's time, we have known that the relationship between psyche and soma is much too complex for us to be able to draw such a simple line between physiological and psychological factors.

In 1926, Freud writes: "It cannot be for nothing that the common usage of speech should have created the notion of internal, mental pain and have treated the feeling of loss of object as equivalent to physical pain" [12]. Although pain manifests itself through a multitude of different forms (it can be persistent, periodic, chronic, accidental, linked to an illness to a variable degree, with or without a localized bodily source, etc.), it is always caught up in the psychic reality of the subject, including both conscious and unconscious dimensions.

We would like to conclude by arguing that in order to transcend these epistemological and ideological divisions we should instead understand pain as a sign. As such, it is in- deed a symptom in the medical sense; however, it isn't one for psychoanalysis, for whom a symptom always functions as a message, a compromise and an expression of desire.

For the clinician, a sign is not something to be interpreted. Instead, it alerts us to the experience of loss, which is the foundation and driving force of the subject's construction, of his very condition as a human being.

There is no doubt that -- as we often hear -- "pain is a scandal!" What we have tried to explain in this short paper is that it is a scandal in the constitution of the $I$, of the subject and his body ${ }^{2}$. This means that pain perhaps does not have a specific function, but it is itself a function.

Pain is an objective sign: not only for the suffering subject, who can no longer ignore a certain affect (while a feeling of anxiety or sadness may more easily be dismissed), but possibly also for the person to whom the subject looks for help.

The work of therapy, regardless of its form and methods (chemical, physical, psychological or psychoanalytical), can ultimately only begin by offering the subject something in the place of his loss -- a word, drug, placebo, etc. -- so that he can again exist in the "silence of the organs".

\section{CONFLICT OF INTEREST}

The author confirms that this article content has no conflict of interest.

\section{ACKNOWLEDGEMENTS}

Declared none.

\section{PATIENT'S CONSENT}

Declared none.

\section{REFERENCES}

[1] Queneau R. Children of Clay. Minneapolis, MN: Consortium 1998; 278.

[2] Croix L. Au-delà des maux. La douleur: nécessité logique de son statut métapsychologique [Doctorate unpublished dissertation] Paris: University of Paris XIII; sept. 1996. 670 pages, French.

[3] Croix L. La douleur en soi, de l'organique à l'inconscient. Paris: Erès; 2002, 302 p.. French. 2004, "L'inévitable douleur du sujet", Cahiers de psychologie clinique, $\mathrm{n}^{\circ} 23$, Bruxelles, De Boeck Université, French. 2009, « Der unabwendbare Schmerz des Subjekts ", psychologie Et gesellschaftskritik, 33. Jahrgang, nr 131, Heft 3 , Schmerz, Pabst Science Publishers, Deutsch.

[4] Bernard C. An Introduction to the Study of Experimental Medicine. NYC: Courier Dover Public; 2012: p. 35.

[5] Freud S. The Psychopathology of Everyday Life: Forgetting, Slips of the Tongue, Bungled Actions, Superstitions and Errors. Standard Edition, 7: 253. London: Hogart Press; 1901.

[6] Freud S. Five Lectures on Psycho-analysis. Standard Edition, 11: 51. London: Hogart Press; 1910.

[7] Canguilhem G. On the Normal and the Pathological. New York: Zone Books; 1999: p. 93.

\footnotetext{
${ }^{2}$ This is why the memory of pain is something quite specific: we remember that we felt pain, but not the painful sensation itself. Pleasure, such as kissing or caressing someone, can be remembered and then re-lived in fantasy; pain on the other hand remains an experience we cannot simply store and recall - yet it leaves an indelible trace that can later be reinvested.

3 "Health is life lived in the silence of the organs." Leriche, R., quoted in Canguilhem [13].
} 
[8] Freud S. The Psychotherapy of Hysteria from Studies on Hysteria. Standard Edition, 2: 264. London: Hogart Press; 1893.

[9] Croix L. Douleur. In de Mijolla A, Editor. Dictionnaire international de la psychanalyse. Paris: Calmann-Lévy; 2002, pp. 474-5. (French).

[10] Schilder PF. The Image and Appearance of the Human Body: Studies in the Constructive Energies of the Psyche (1935). London: Routledge; 1999.
[11] Freud S. The Ego and the Id. Standard Edition, 19. London: Hogart Press; 1923: pp. 24-25.

[12] Freud S. Inhibitions, Symptoms and Anxiety. Standard Edition, 20: 170. London: Hogart Press; 1926: p. 276.

[13] Canguilhem G. On the Normal and the Pathological. New York: Zone Books; 1999: p. 91.

Received: March 31, 2014

Revised: June 10,2014

Accepted: June 13, 2014

(C) Laurence Croix; Licensee Bentham Open.

This is an open access article licensed under the terms of the Creative Commons Attribution Non-Commercial License (http://creativecommons.org/licenses/by-nc/3.0/) which permits unrestricted, non-commercial use, distribution and reproduction in any medium, provided the work is properly cited. 